\title{
ARTICLE \\ An Analysis of the Project Incubation Model of Self-produced TV Dramas in the New Media Era
}

\author{
Xiaoxuan Zhao* \\ Beijing Radio \& Television Station, China
}

Received: 13 December 2021; Accepted: 27 December 2021; Published: 31 December 2021

\begin{abstract}
With the advent of the information age, the application of digital technology on the Internet has become more and more popular. Mobile phones, the Internet and other emerging media have brought a drastic impact on the traditional media era, and the status of traditional media is slowly weakening. Nowadays, new media devices and video websites are gradually becoming active in people's lives, and the increasingly sophisticated digital means have led to the rapid rise of new media. Against this backdrop, traditional media are being squeezed to a great extent. In addition to being dominated by new media in terms of communication channels, the voice of traditional media in the market is also threatened to a certain extent. In addition to the problems of the traditional media themselves, and the lagging nature of the traditional media that is not in tune with the development of the times, the traditional media industry, especially the TV side and TV people, are gradually facing more pressure. Under pressure, there must be innovation. How traditional TV media can change and innovate requires us to rise to the occasion and be fully prepared for the current environment, and self-produced dramas are one of the paths that TV stations need to explore.
\end{abstract}

Keywords: Self-produced drama, Television, In-depth front-end, Copyright lock, Win-win

\section{The Impact and Influence of Traditional Television Media in the New Media Era}

\subsection{Technological Progress, Prompting the Renewal of Viewing Methods}

Video websites have two characteristics in comparison with television: one is the non-linearity in time, and the other is the personalization in space. Viewers can no longer wait for the start time of the TV station, and can choose the programmes they want to watch at will, and can generate an interactive experience through the Internet. This new way of viewing directly transforms the audience from passive "viewers" to active "users". With the rapid advent of the multi-screen era, the "living room culture" on which television is most dependent will increasingly become a niche phenomenon. As an important mass media, television may not die out for a long time, but the impact of the Internet on traditional television will be far stronger than the impact of television

\footnotetext{
*Corresponding Author:

Xiaoxuan Zhao,

Beijing Radio \& Television Station, China;

Email:18601127952@163.com
} 
on radio, as technological progress is unstoppable.

\subsection{The Revenue Models are very Different, Resulting in a Gradual Increase in the Difference in Revenue between New Media and Traditional TV Media}

For traditional TV media, its source of survival is more from the support of advertising business. However, with the advent of the new media era, advertisers have segmented the user market more clearly and are demanding more and more from the platforms they work with in terms of advertising needs. Advertisers are beginning to select platforms for placement based on user characteristics, resulting in a significant reduction in the range of advertising business available to traditional TV media and a serious diversion of the industry profits that can be made.

In contrast, the new media have ample operating capital thanks to their multi-channel revenue streams and flexible financing options. The overbearing capital of video sites fully demonstrates the nature of capital, as they push up all commercially valuable programmes, push up the price of actors, push up the total cost of programmes, push up the status of marketing, and push up the market value of the industry as a whole, even with the effect of pushing up TV ratings. It can be said that the power of capital is everywhere in the film and television industry nowadays. In the past, the "production fee-advertising revenue-production fee" agricultural production model of television stations was extremely difficult to defend against the aggressive capital offensive.

\subsection{Different Mechanisms Lead to an Increasing Brain Drain}

In most industries where competition exists, stateowned units are overwhelmed in the face of private enterprises. The state-owned system of television stations is no exception, and the administrative-based system that has developed over the years contrasts sharply with the pursuit of maximum benefit by private enterprises. Due to a consistent lack of training and attention to talent, TV stations have now become a net outflow of talent from private enterprises. The talents that TV stations have worked so hard to cultivate are easily poached. The saying "people are the foundation of everything" is not reflected in many TV stations.

\subsection{Different Regulatory Requirements Lead to Different Scales of Programming for New Media and Traditional TV Media}

All video websites position themselves as high-tech enterprises rather than media, which has allowed them to avoid content regulation to a great extent. While calls for the same standard of censorship are increasing and the authorities are stepping up their monitoring efforts, the fact remains that more and more influential variety shows and TV dramas that do not meet TV broadcast standards can be presented on the internet, where they have a wider distribution. As a result, more and more viewers are being converted to online viewers with these programmes.

\section{Returning to Self-production is the Way of Survival and Innovation for TV Stations}

With the rapid progress of technology, the challenge of new media to TV media will become greater and greater. Therefore, as a traditional industry, only by changing the original production model and changing the way of thinking can we survive and develop in the midst of change. The first step is to change the mindset of "separation of production and broadcasting".

In the era of television dominance, the slogan of "separation of production and broadcasting" was introduced to promote the development of the industry. Non-state companies have far surpassed state-owned enterprises and institutions in terms of output and market value, and the quality of their programmes is becoming higher and higher, gradually becoming the mainstream of the market. In this situation, more and more programmes have shifted to production by companies, while the business of TV stations has shrunk more and more. In the Internet era, TV stations whose platform value has declined sharply have all suffered to varying degrees from the loss of business back then and are struggling ${ }^{[1]}$.

The best situation among the major TV stations is undoubtedly Hunan TV, where the various plans that began more than ten years ago have finally shown their value today: a highly unified approach to programme production, a flexible and efficient talent mechanism, and a highly market-oriented listed company, which together have created the top-ranked TV and Internet platform today.

In addition to Hunan, Jiangsu, Zhejiang and Shanghai in the Yangtze River Delta, with the region's ancient affluence and talent, as well as its position at the forefront of reform and opening up over the years, have also taken the lead and developed their own paths in line with their own characteristics, becoming an important TV station alongside Hunan.

Other provincial TV stations, which are also important TV stations in China, are constrained by their environment and lag behind several major stations in Jiangsu, Zhejiang, Shanghai and Hunan in terms of market development. 
For example, Beijing, which has missed out on the capital expansion of television, has to hold on to the two most marketable programme genres of variety and drama, especially the highly capitalised drama industry, which is where we can seek a breakthrough in the face of the diverse and complex changes in the industry.

Objectively speaking, it is not enough for TV stations that belong to the top tier at the level of TV drama broadcasting to rely on broadcasting alone. Firstly, pure procurement is equivalent to living off the sky, whether there are quality dramas and whether we can get a hit drama all depends on the market, this is because as a broadcasting platform, it lacks control over the front end of production; secondly, nowadays, the procurement price of dramas and the advertising production value are increasingly mismatched, and broadcasting top dramas is increasingly becoming a luxury; thirdly, compared to news and variety shows, dramas lack iconic and brand recognition Thirdly, compared to news and variety shows, dramas lack iconic and brand recognition, and the stacking of top dramas may not necessarily create a top effect ${ }^{[2]}$.

In this situation, getting involved in the front end of production, in the investment and creation of television series, would go some way to alleviating, and getting out of, the dilemma, yielding some benefits as follows.

\subsection{Facilitating TV Stations to Lock in Boutique Dramas in Advance}

By entering the market with investment in the creation of TV dramas, TV stations can further enhance their voice in the production of TV dramas, especially quality dramas, by ensuring that they are involved at the very beginning of the creation process, making it easier for them to lock in the rights and prevent projects that they have invested their efforts in from eventually falling through the cracks.

\subsection{Meeting the Needs of TV Station Layout}

In addition to the basic supply of space on TV and film channels, it also ensures that the station's own copyrighted masterpieces are produced at major promotional points, thus meeting the needs of layout while emphasising quality.

\subsection{Reducing the Cost of Drama Purchase by Television Stations}

The participation of TV stations in the creation of TV drama investment helps to balance prices and get TV dramas of satisfactory quality, at reasonable prices and with a slight surplus, so as to reduce the cost of purchasing dramas.

\subsection{Inward Cultivation of Talents and Training of Teams}

By investing in the creation of drama series led by the station, the team can be trained, producing and editorial talents can be nurtured, and attempts can be made for the station to realise business transformation.

\subsection{Broadening Product Lines and Revenue Channels Outwards}

As an industry, the revenue of TV dramas is not only from TV and internet rights sales, but also from implantation of advertisements, copyright adaptations and even peripheral product development, which will lead to more and broader business types, thus broadening the revenue channels and entering into a wider range of businesses, such as movies, animation, etc.

\section{Integrating Strengths, Adjusting Mechanisms and Seeking Development in a Market-oriented Environment}

It is of course a wonderful vision to produce products that meet one's own needs and also generate more benefits. But in today's highly marketed world of television drama production, where state-owned enterprises are still stretched to the limit, is it still possible for them to produce their own dramas as more strictly controlled institutions, especially secondary institutions such as television stations, which are under strict financial control?

Although it is difficult, if we can integrate some of the existing advantages and adjust some of the original institutional constraints, there is still a small possibility for TV stations to produce their own dramas.

Firstly, there must be a high degree of unity of consciousness at the television station level. Television stations must realise that when they are involved in production, they face fierce competition, and that in competition with established companies, especially private ones, state-owned entities do not have an advantage. As a result, the station's own production must be carried out in a way that is "decided by the station, relying on a platform, implemented by the company and closely linked". The production of TV dramas is now a relatively well-developed and complete industry chain, with a high level of capital investment and entry into the production of TV dramas being a distinctive feature, with hundreds of millions of dollars of investment and overcapacity making TV dramas no longer just artistic creations. Therefore, it is necessary to reach an internal agreement on whether to produce TV dramas, what mode of production to adopt 
and what creative direction to set, and to rely on one's own broadcasting platform in order to gradually develop the competitiveness of TV dramas.

Secondly, self-produced dramas must be produced in collaboration with other television stations. Nowadays, the production of TV dramas is no longer a single-way model of "capitalist-script-director-actor-airing platform", and in the current TV drama market, multi-party cooperation is crucial to the output of a TV drama. In the current TV drama market, multi-party cooperation is crucial to the production of a TV drama. At the same time, external cooperation should follow the laws and rules of the market, with all parties on an equal footing, and without the boss mentality.

Thirdly, the business of self-produced dramas is a market-oriented activity that requires capitalisation, and in view of this, the term "purchase instead of investment" has arisen. As a special fund for TV stations, it is difficult to convert the purchase money into investment directly. In contrast, bank loans and cultural funds are financing methods that TV stations can consider, using the purchase money to leverage the capital market and make it investable.

Fourthly, for the station's self-produced drama business, a linkage mechanism needs to be established within the station in particular, and a sound corresponding fault-tolerant and incentive mechanism should also be set up to break down some inherent barriers so that the flow of self-produced drama projects within the station can proceed smoothly. The first and foremost responsible parties are the enterprises and film and television-related departments of the TV stations to which they belong. Inevitably, TV tower companies will have to rely on the support of the station in the early stages, but they must establish their own business model as soon as possible; the TV station's film and television-related departments must monitor the entire process of self-produced drama projects; and other business and functional departments of the TV station must also give substantial support. Without the strong support of TV stations, self-produced dramas are unlikely to succeed.

Fifthly, TV stations must establish effective personnel mechanisms to nurture talent and reduce brain drain. The market is ruthless and requires hard power, the core of which comes from talent. If the personnel mechanism is not adjusted, the traditional media will easily form a situation where the "backbone is lost", "a springboard for young people" and "a retirement home". In the various aspects of self-produced drama production, professionals such as directors and scriptwriters may not need to be trained by the TV station itself, but producers and editorial teams need to be trained from within the station. It is unrealistic to expect external monks to recite good scriptures at the early stage of the business without fully opening up the capital, channels and mechanisms; the only way to know what kind of talents to bring in and how to use and treat them is to first improve ourselves and gradually train and build a team to form a stable business scale and model. Therefore, first we need to lay the foundation for talent internally, starting with building such a team from within the film and television department, linking up and channelling with companies owned by the station, and using the relatively flexible mechanisms of the companies to form a production team for television dramas.

Finally, I believe that the self-produced drama business should be steadily pursued and should not be over-scaled, drawing on more exotic dramas. In the initial stage, it should be mainly exploratory, with individual projects, trying first, finding problems and solving them on a small scale, and then expanding when all processes and awareness are perfected and unified.

\section{Grasping the Source and Production: The Project Incubation Model for Television Self- produced Dramas}

The current incubation model for self-produced TV drama projects should mainly consist of two key words: "grasping the source" and "grasping production".

\subsection{Grasping the Source}

Catching the source refers to the source from which the project was initially hatched. We believe that there are two types of sources to be caught by the station's selfproduced drama, namely: a major publicity node to form the planning source (mainly by the stations); and a mature commercial project planning case provided by a social company as the source (mainly by the social companies).

\subsection{Grasping Production}

The production aspect of self-produced dramas begins with lending as much strength as possible to large companies that have strengths and productions and have worked with the station, so as to learn from the experience of the company's operations, and also to gradually cultivate promising teams and companies and identify promising writers, directors and actors, so as to lay the foundation for the further development of the stationowned company.

By focusing on the source and on production, the incubation of the station's self-produced drama projects can proceed in an orderly manner and ensure that the projects run properly and efficiently at any stage. 


\subsection{Work together and Joint Investment from Various TV Networks: The Business Model for TV Self-produced Dramas}

From the perspective of the business model, self-produced TV dramas can be jointly incubated by the station with other platforms (other TV channels, video websites) and companies, so that the project is promoted at the request of each platform from the early stage of creativity, minimising project risks, with each platform party and other investors and producers investing together and sharing risks and interests, transforming the "production $\rightarrow$ sales model" The project is transformed into a bespoke product based on market demand (platform).

This business model is mainly applicable to TV dramas that can reach the level of broadcast on satellite TV, and it can follow the following process.

-Initiating: TV station, network or social company

-Demonstration: TV station + other TV stations + network, with the premise of broadcasting for demonstration

-investment: TV station-owned company + another companies + website + social companies

-Production and distribution: social companies are responsible for the production, with each platform monitoring the quality throughout

-Broadcast: each platform will broadcast together as agreed

-Distribution of benefits: several parties share the copyright and other revenues are distributed as agreed

Through this business model, a good combination can be achieved in terms of both TV stations' own research and development and external cooperation, which helps to further open up the cooperation between TV stations and other TV stations, and TV stations and networks, officially turning the self-produced drama business into a promising and sustainable business, rather than just satisfying the need to broadcast and survive.

\section{Broadening the Market and Seeking Development: Vision and Goals for Self-produced Dramas}

In order for the self-produced drama business to continue to thrive, TV stations need to start developing a vision and higher goals for their self-produced drama business.

\subsection{TV Stations Should Go Deep into the Front- end and Take Ownership}

Delve into the front end of production and establish a new self-production system led by TV stations to increase the platform's master control and commercial interests. Through investment, buyouts, IP development and original scripts, they can fully grasp the right to speak about their works and create a series of high-quality dramas. The brand name of "TV production" will be formed.

\subsection{Deep Processing and Industry-wide Development of IP}

Deep processing of purchased or original IP to make it have conversion value, so as to achieve mutual benefits with animation, film, games, derivatives and other industries.

\subsection{Continuing to Broaden the Market}

We will not only aim to be the only broadcasting platform, but also to serve the needs of other broadcasting platforms, and through continuous market expansion, we will broaden our self-produced drama business to become a sustainable and important business for the station.

\section{Conclusions}

In the era of new media, traditional television is no longer the dominant screen. The impact of new media on traditional television is not only to change the media terminal, but fundamentally, it is a challenge to the whole traditional media operation thinking. While there are certainly pressures in this process, there are also opportunities to be found. At a time of media convergence, traditional TV media should actively embrace the new media, while at the same time keep the righteousness and innovation, and seek new ideas, ultimately forming a mutually beneficial and win-win situation.

For some time now, television stations have begun to lag behind in the media camp. Faced with the difficulties of the times, we must set out again and muster the courage to strive for innovation in order to achieve better survival and development. As major TV stations have made their presence felt in recent years, they are still an important media and market terminal in China. Although the competition in the media is cruel and unpredictable, there is still a foundation for new life with the accumulated heritage of TV stations over the years, and self-produced TV dramas are undoubtedly the most worthy direction to try to break through, and it is also worthwhile for TV people to embrace better prospects for this.

\section{References}

[1] Wang, Ch.H., Wang, R., 2014. The advantages and challenges of traditional television in the new media era. Cable TV Technology. (8), 32-34.

[2] Dong, Zh.N., 2016. Bottlenecks and innovative breakthroughs in the development of television media in the new media era. News Communication. (3), 25-28. 